DOI: $10.1515 /$ pts-2017-0004

\title{
APPLICATION OF LOCAL FOURIER TRANSFORM TO \\ MATHEMATICAL SIMULATION OF SYNCHRONOUS MACHINES WITH VALVE EXCITATION SYSTEMS
}

\author{
A. Fedotov, E. Fedotov, K. Bahteev \\ Kazan State Power Engineering University \\ 51 Krasnoselskaya Str, Kazan, 420034, RUSSIA
}

\begin{abstract}
The article proposes a method of mathematical simulation of electrical machines with thyristor exciters on the basis of the local Fourier transform. The present research demonstrates that this method allows switching from a variable structure model to a constant structure model. Transition from the continuous variables to the discrete variables is used. The numerical example is given in the paper.
\end{abstract}

Keywords: mathematical modelling, thyristor exciter, local Fourier transform, synchronous machine, electromagnetic transients.

\section{INTRODUCTION}

Mathematical models of synchronous machines used for the study of transients in the majority of cases are based on continuous mathematical methods. It is justified for dynamoelectric drivers because both processes and modelled objects are continuous in essence, as well as in principles of operation. However, there are key elements - thyristors - in an excited circuit of the synchronous machine. The complete system of differential equations describing the synchronous machine together with valve exciter contains periodic coefficients and has the variable structure, which is changing non-linearly in time.

Development of methods of mathematical simulation [1], [2] has allowed justifying feasibility of transition to the discrete sampling of regime parameters that, on the one hand, provides the fastest processing of information, and, on the other hand, reflects specifics of operation of valve elements present in the excitation system of the synchronous generators and engines.

The methods of the organisation of discrete mathematical models for electrical circuits with valve converters are well developed in [2]-[6]. It has been shown that by means of the local Fourier transform (LFT) it is possible to obtain mathematical models in a finite-difference form or rather step images for the synchronous machines with an independent thyristor and self-excitation. The switching of the 
valves causing local indignations of the mode is not taken into consideration, and the created models describe macro processes as they are the main object of the research.

\section{METHOD}

The LFT method is as follows. We consider continuous function $f(t)$ (Fig. 1) and also allocate some $m$ interval to borders $\left[t^{(m)} ; t^{(m)}+h^{(m)}\right]$. We periodically continue the function $f(t)$, considered only within the limits of the allocated interval, on the both sides of the allocated interval (Fig. 1). Thereby we receive new function $f_{p}(t)$, which has the following properties: first, it is periodic with the period $h^{(m)}$; secondly, on the interval of values of argument $t \in\left(t^{(m)} ; t^{(m)}+h^{(m)}\right)$, it identically coincides with the required function, i.e., $f_{p}(t) \equiv f(t)$; thirdly, in boundary points $t=t^{(m)}$ and $t=t^{(m)}+h^{(m)}$ function $f_{p}(t)$ has ruptures of the first type.

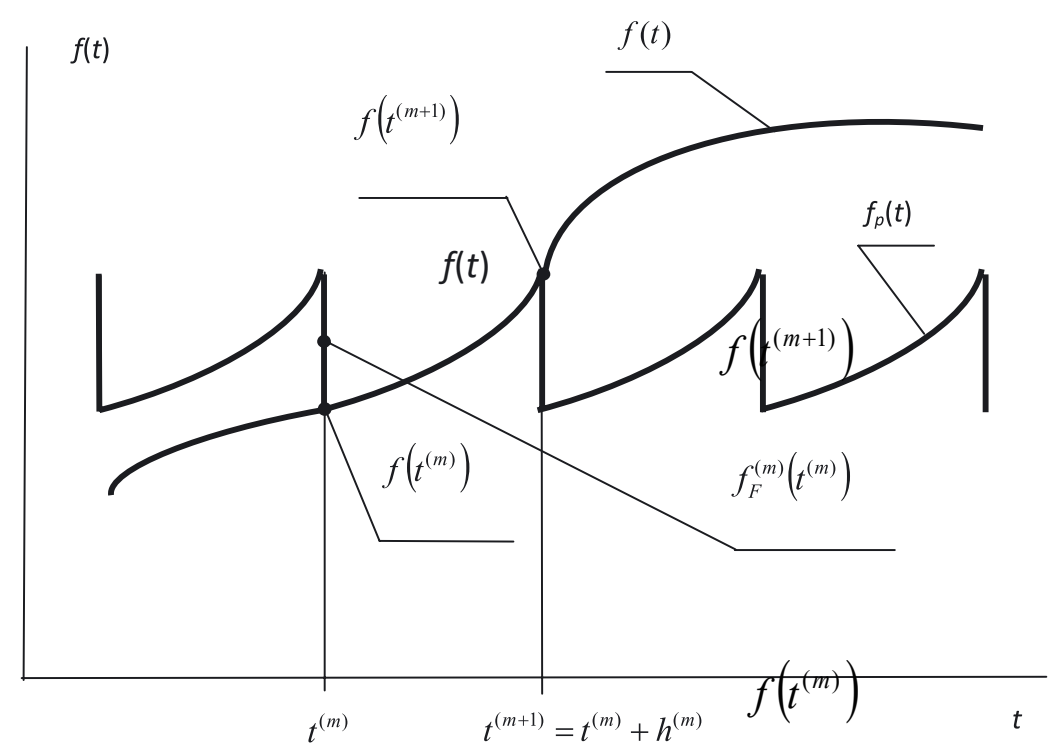

Fig. 1. The periodization of non-periodic functions.

It is known that such a function can be represented by the Fourier series $f_{F}(t)$, in addition

$$
\begin{aligned}
& f_{p}^{(m)}(t) \equiv f_{F}^{(m)}(t)=C_{0}^{(m)}+\sum_{n=1}^{n=\infty} C_{k}^{(m)} \cos k\left(t-t^{(m)}\right)+S_{k}^{(m)} \sin k\left(t-t^{(m)}\right), \\
& k=\frac{2 \pi n}{h^{(m)}} ; \quad n=0, \pm 1, \pm 2, \ldots ; t \in\left(t^{(m)} ; t^{(m)}+h^{(m)}\right) ; \\
& C_{0}^{(m)}=\frac{1}{h^{(m)}} \int_{t^{(m)}}^{t^{(m)}} f(t) d \theta ; h_{k}^{(m)}=\frac{2}{h^{(m)}} \int_{t^{(m)}}^{t^{(m)}} f(t) \cos k\left(t-t^{(m)}\right) d \theta ; \\
& S_{k}^{(m)}=\frac{2}{h^{(m)}} \int_{t^{(m)}}^{t^{(m)}} f(t) \sin k\left(t-t^{(m)}\right) d \theta .
\end{aligned}
$$


Since the function $f_{p}(t)$ in points $t=t^{(m)}$ and $t=t^{(m)}+h^{(m)}$ has discontinuities, for the Fourier series the following relations are valid:

$$
\begin{aligned}
& f_{F}\left(t^{(m)}\right)=f_{F}\left(t^{(m)}+h^{(m)}\right)=f\left(t^{(m)}\right)+\frac{1}{2}\left\{f\left(t^{(m)}+h^{(m)}\right)-f\left(t^{(m)}\right)\right\}= \\
& =f_{l}^{(m)}+\frac{1}{2} \Delta f_{l}^{(m)}=C_{0}^{(m)}+\sum_{n=1}^{\infty} C_{k}^{(m)} .
\end{aligned}
$$

Expression (2) is one of the main equations used in this method, because it relates the continuous parameters (Fourier series) with discrete - with the countdown of function $f_{l}^{(m)}$ (i.e., with its value in the point $t=t^{(m)}$ and with its final difference $\Delta f_{l}^{(m)}$.

The following integral is the local Fourier transform (F-conversion):

$$
F\{f(t)\}=F(m, k)=\frac{2}{h^{(m)}} \int_{t^{(m)}}^{t^{(m)}} f(t) e^{-j k\left(t-t^{(m)}\right)} d t
$$

where $k=\frac{2 \pi n}{h^{(m)}}=\omega^{(m)} n ; \quad n=0, \pm 1, \pm 2, \ldots ; m=1,2, \ldots$, and $F(m, k)$ is a local image (image A) of function $f(t)$, wherein

$$
f\left(t^{(m)}\right)=\frac{1}{2} \sum_{n=-\infty}^{\infty} F(m, k)-\frac{1}{2} \Delta f\left(t^{(m)}\right)=\frac{1}{2} F(m, 0)+\sum_{n=1}^{\infty} C_{k}^{(m)}-\frac{1}{2} \Delta f\left(t^{(m)}\right)
$$

Expression (4) is already sufficient to organise numerical procedures of the solution of the linear differential equations with the constant coefficients, leading them in accordance with (4) to the final-difference equations. We consider the analytical possibilities of the F-image summation according to (4). If they can be presented in the form

$$
F(m, k)=\sum_{i=1}^{I} D(j k) A_{i}(m)
$$

on the basis of the theorem of deductions, we obtain

$$
\sum_{n=-\infty}^{\infty} F(m, k)=-j \pi \sum_{i=1}^{I} A_{i}(m) \sum_{s=1}^{S} b_{s i} \operatorname{ctg}\left(j \pi a_{s i}\right)
$$

where $S$-the number of the function poles (simple) of a complex variable $D(p)$, whose deductions in poles $p=a_{s i}$ are equal to $b_{s i}$. $D(p)$ turns out from $D(j k)=D\left(j \omega^{(m)} n\right)$ by replacement $j n=p$. It is convenient to use in case of the valid values $a_{s i}$. 


$$
j \pi c t g\left(j \pi a_{s i}\right)=\pi c t h\left(\pi a_{s i}\right) .
$$

If $D(j k)$ forms final sequence of the $n$, formula (6) is inapplicable and it is necessary to use formula (5) of direct summation.

Thus, we receive $f\left(t^{(m)}\right)=\frac{-j \pi}{2} \sum_{i=1}^{I} A_{i}(m) \sum_{s=1}^{S} b_{s i} \operatorname{ctg}\left(j \pi a_{s i}\right)-\frac{1}{2} \Delta f\left(t^{(m)}\right)$.

We show the use of local Fourier transform for the formation of the discrete mathematical model of the synchronous machine with the system of independent thyristor excitation from the transformer connected to an electrical network (Fig. 2.)

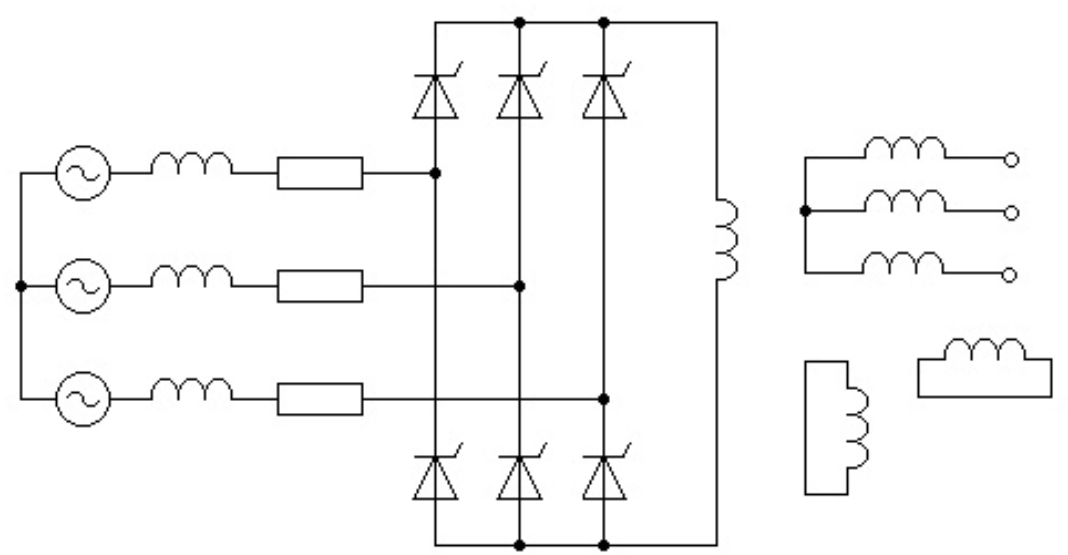

Fig. 2. The schematic diagram of the synchronous machine and its exciter.

Resistances $r_{c}, x_{c}$ correspond to a field winding supply circuit from alternating current, EMFs $E$ forms a direct sequence.

We accept the following assumptions: input equations of the synchronous machine use the model of Park-Goreva with the equivalenting conversion of damping circuits of one winding in a longitudinal axis and one winding in a lateral axis; the axis $d$ advances an axis $q$. The valves of the managed converter, which is collected on a three-phase bridge circuit, are considered ideal; they work in the main mode - the mode of the serial conductivity of two and three valves, and the angle of thyristors control $\alpha$ is digitized from null value of the corresponding phase EMF. In the equations of the synchronous machine, we save the standard designations [7]. In the equations of discrete model, we use the "walking" coordinate system, which is displaced giving the next control signal on thyristor in an angular measure of $\pi / 3$ radians (duration of an interval of repeatability of the converter).

The classical equations of Park-Goreva for the synchronous machine are written using a system of the relative units $x_{a d}$ : 


$$
\left.\begin{array}{l}
-u_{d}=r i_{d}+\frac{d}{d \theta}\left(x_{d} i_{d}+x_{a d} i_{f}+x_{a d} i_{1 d}\right)+x_{q} i_{q}+x_{a q} i_{1 q}, \\
-u_{q}=r i_{q}+\frac{d}{d \theta}\left(x_{q} i_{q}+x_{a q} i_{1 q}\right)-\left(x_{d} i_{d}+x_{a d} i_{f}+x_{a d} i_{1 d}\right), \\
u_{f}=r_{f} i_{f}+\frac{d}{d \theta}\left(x_{a d} i_{d}+x_{f} i_{f}+x_{a d} i_{1 d}\right), \\
0=r_{1 d} i_{1 d}+\frac{d}{d \theta}\left(x_{a d} i_{d}+x_{a d} i_{f}+x_{1 d} i_{1 d}\right), \\
0=r_{1 q} i_{1 q}+\frac{d}{d \theta}\left(x_{a q} i_{q}+x_{1 q} i_{1 q}\right) .
\end{array}\right\}
$$

We connect through the equations the electric field of a winding of excitement and a power line. In the $\mathrm{m}$-th local interval of recurrence of the converter within duration of the commutation of the phases $\gamma$ connected to switching of valves, the following equation is obtained in the system of the walking coordinates:

$$
u_{f}^{(m)}=\sqrt{3} E \cos (\theta-\pi / 3)-2 r_{c} i_{f}^{(m)}-2 x_{c} \frac{d i_{f}^{(m)}}{d \theta}+r_{c} i_{\gamma}^{(m)}+x_{c} \frac{d i_{\gamma}^{(m)}}{d \theta},
$$

where $\theta=\omega t, \theta \in[\alpha ; \alpha+\gamma] ; \quad i_{\gamma}^{(m)}-$ the exciter current phase, ending switching, and $i_{\gamma}^{(m)}(\alpha)=i_{f}^{(m)}(\alpha), \quad i_{\gamma}^{(m)}(\alpha+\gamma)=0$.

Outside the switching interval, when $\theta \in[\alpha+\gamma ; \alpha+\pi / 3]$ it is also possible to use equation (7) in case $i_{\gamma}^{(m)} \equiv 0$.

If we apply the local integral conversion [1], which is a special case of LFT, to equation (7), i.e., according to terminology [1] to pass to the "step images" of variables

$$
F_{s}=\frac{3}{\pi} \int_{\alpha}^{\alpha+\pi / 3} f(\theta) d \theta
$$

considering boundary conditions for switching current $i_{\gamma}^{(m)}$ we receive

$$
U_{f s}^{(m)}=\frac{3 \sqrt{3}}{\pi} E \cos (\alpha-\pi / 6)-2 r_{c} I_{f s}^{(m)}-\frac{3}{\pi}\left(x_{c}-r_{c} \gamma / 2\right) I_{f l}^{(m)}-\frac{6}{\pi} x_{c} \Delta I_{f l}^{(m)},
$$

where the lower $s$ index belongs to the mean value of a required variable on $m$ interval of recurrence of the converter, the index $l$ corresponds to the value of the variable in the switching point, i.e., at the time of submission of the controlling signal to the next thyristor of the converter that is illustrated by the following formula:

$$
\Delta I_{f l}^{(m)}=i_{f}^{(m)}(\alpha+\pi / 3)-i_{f}^{(m)}(\alpha)=I_{f l}^{(m+1)}-I_{f l}^{(m)} .
$$

The rectilinear approximation is used in integration of equation (7). Expression (8) describes a response external characteristic of the transformer in the discrete variables. It is obtained mathematically within the accepted assumptions. Taking into consideration smoothness of the straightened current, we assume that $I_{f s}^{(m)}=I_{f l}^{(m)}$. 
Let us assume that the synchronous generator mentioned above has outputs connected to the active and inductive load $r_{w}, x_{w}$.

$$
\left.\begin{array}{l}
u_{d}=r_{w} i_{d}+x_{w} \frac{d i_{d}}{d \theta}+x_{w} i_{q}, \\
u_{q}=r_{w} i_{q}+x_{w} \frac{d i_{q}}{d \theta}-x_{w} i_{d} .
\end{array}\right\}
$$

Having applied LFT to equations (6), (7) and (9), we receive the equations of the synchronous generator together with its activator in the field of F-images

$$
\left.\begin{array}{l}
\left(r_{s}+j k x_{d s}\right) \dot{I}_{d}(m, k)+j k x_{a d} \dot{I}_{f}(m, k)+j k x_{a d} \dot{I}_{1 d}(m, k)+x_{q s} \dot{I}_{q}(m, k)+ \\
+x_{a q} \dot{I}_{1 q}(m, k)=-\frac{6}{\pi} x_{d s} \Delta I_{d}^{(m)}-\frac{6}{\pi} x_{a d} \Delta I_{f}^{(m)}-\frac{6}{\pi} x_{a d} \Delta I_{1 d}^{(m)}, \\
-x_{d s} \dot{I}_{d}(m, k)-x_{a d} \dot{I}_{f}(m, k)-x_{a d} \dot{I}_{1 d}(m, k)+\left(r_{s}+j k x_{q s}\right) \dot{I}_{q}(m, k)+ \\
+j k x_{a q} \dot{I}_{1 q}(m, k)=-\frac{6}{\pi} x_{q s} \Delta I_{q}^{(m)}-\frac{6}{\pi} x_{a q} \Delta I_{1 q}^{(m)}, \\
j k x_{a d} \dot{I}_{d}(m, k)+\left(r_{f s}+j k x_{f s}\right) \dot{I}_{f}(m, k)+j k x_{a d} \dot{I}_{1 d}(m, k)=-\frac{6}{\pi} x_{c} I_{f l}^{(m)}+ \\
+\dot{B}(m, k)\left(r_{c}+j k x_{c}\right) I_{f l}^{(m)}-\frac{6 \sqrt{3}}{\pi} E \frac{\cos (\alpha-\pi / 6)+j k \sin (\alpha-\pi / 6)}{k^{2}-1}- \\
-\frac{6}{\pi} x_{a d} \Delta I_{d}^{(m)}-\frac{6}{\pi} x_{f s} \Delta I_{f}^{(m)}-\frac{6}{\pi} x_{a d} \Delta I_{1 d}^{(m)}, \\
j k x_{a d} \dot{I}_{d}(m, k)+j k x_{a d} \dot{I}_{f}(m, k)+\left(r_{1 d}+j k x_{1 d}\right) \dot{I}_{1 d}(m, k)= \\
=-\frac{6}{\pi} x_{a d} \Delta I_{d}^{(m)}-\frac{6}{\pi} x_{a d} \Delta I_{f}^{(m)}-\frac{6}{\pi} x_{1 d} \Delta I_{1 d}^{(m)}, \\
j k x_{a q} \dot{I}_{q}(m, k)+\left(r_{1 q}+j k x_{1 q}\right) \dot{I}_{1 q}(m, k)=-\frac{6}{\pi} x_{a q} \Delta I_{q}^{(m)}-\frac{6}{\pi} x_{1 q} \Delta I_{1 q}^{(m)},
\end{array}\right\}
$$

where $r_{s}=r+r_{w}, x_{d s}=x_{d}+x_{w}, x_{q s}=x_{q}+x_{w}, r_{f s}=r_{f}+2 r_{c}, x_{f s}=x_{f}+2 x_{c}$.

The complex coefficient $\dot{B}(m, k)$ that enters equation (10) pays off in the following equation:

$$
\dot{B}(m, k)=\frac{6}{\pi} \frac{1-j k \gamma-e^{-j k \gamma}}{k^{2} \gamma} .
$$

Complex variables are convenient if we pass to the finite-difference equations in the analytical view from equation (5). If in equations (10) we pass from complex to the valid variables by changeover

$$
\dot{I}_{i}(m, k)=I_{i}^{c}(m, k)+j I_{i}^{s}(m, k), \quad i=d, q, f, 1 d, 1 q
$$

and calculate a limited row:

$$
f_{l}^{(m)}=\frac{1}{2} F(m, 0)+\sum_{n=1}^{N} F^{c}(m, k)-\frac{1}{2} \Delta f^{(m)}, \quad k=\frac{2 \pi n}{h},
$$


where $\mathrm{N}$ - the number of the considered members of a row, we obtain the convenient numerical method for formation of a mathematical model of the synchronous machine of the discrete type of constant structure, in which internal switching transient phenomena are not taken into account.

Irrespective of existence of the gate transformer in a generator exciting circuit the speed of computation in the discrete model is significantly higher than in case of integration of the equations in the instantaneous values of variables in the RungeKutta method.

It is interesting to consider and evaluate the possibility of using the simplified discrete model when the entire range of EMF of network and switching current is not considered in the field of images. In this case, the appropriate equation for a circuit of the excitation winding of the synchronous machine takes the following form:

$$
\begin{aligned}
& j k x_{a d} \dot{I}(m, k)+\left(r_{f s}+j k x_{f s}\right) I_{f}(m, k)+j k x_{a d} \dot{I}_{1 d}(m, k)= \\
& =C \frac{6 \sqrt{3}}{\pi} E \cos (\alpha-\pi / 6)-\frac{6}{\pi}\left(x_{c}-C r_{c} \gamma / 2\right) I_{f l}^{(m)}- \\
& -\frac{6}{\pi} x_{a d} \Delta I_{d}^{(m)}-\frac{6}{\pi} x_{f s} \Delta I_{f l}^{(m)}-\frac{6}{\pi} x_{a d} \Delta I_{1 d}^{(m)}, \\
& C= \begin{cases}1, & k=0, \\
0, & k \neq 0 .\end{cases}
\end{aligned}
$$

It is done in order not to complicate needlessly the mathematical model of the synchronous machine. This example shows that the results of calculations for both models, which show that transition from the continuous model to the discrete one, provide more exact reflection of the occurring processes even in the case of the same initial simplifications.

Example 1. We consider the mode of the three-phase short circuit on the outputs of the idling synchronous generator without damping windings. The generator parameters in relative units:

$$
x_{d}=1.0 ; \quad x_{q}=0.7 ; \quad x_{a d}=0.6 ; \quad x_{f}=1.43 ; \quad r=0.0145 ; \quad r_{f}=0.0015 ;
$$
$r=0.0145 ; \quad r_{f}=0.0015$; excitement data: $x_{c}=0.001 ; r_{c}=0.0002 ; E=0.004$.

The initial value of current of excitement is $i_{f}(0)=1.014$. The comparison of calculation results for the instantaneous values of variables during intervals of the persistence of structure of the transformer (reference model) and in the discrete model (10) showed their almost complete coincidence in switching points.

We also estimate the accuracy of calculations using the simplified model of the exciter (12) where the power-supply circuit of a winding of excitement is described by equation (8). At the same time, we show the sequence of the numerical calculations. equations:

Having passed from complex to the valid variables, we obtain the following 


$$
\begin{aligned}
& {\left[\begin{array}{cccccc}
r & -k x_{d} & 0 & -k x_{a d} & x_{q} & 0 \\
k x_{d} & r & k x_{a d} & 0 & 0 & x_{q} \\
0 & -k x_{a d} & r_{f s} & -k x_{f s} & 0 & 0 \\
k x_{a d} & 0 & k x_{f s} & r_{f s} & 0 & 0 \\
-x_{d} & 0 & -x_{a d} & 0 & r & -k x_{q} \\
0 & -x_{d} & 0 & -x_{a d} & k x_{q} & r
\end{array}\right]\left[\begin{array}{c}
I_{d}^{c}(m, k) \\
I_{d}^{s}(m, k) \\
I_{f}^{c}(m, k) \\
I_{f}^{s}(m, k) \\
I_{q}^{c}(m, k) \\
I_{q}^{s}(m, k)
\end{array}\right]} \\
& {\left[\begin{array}{cccccc}
-x_{d} & -x_{a d} & 0 & 0 & 0 \\
0 & 0 & 0 & 0 & 0 \\
-x_{a d} & -x_{f s} & 0 & -x_{c}+C \frac{r_{c} \gamma}{2} & C \frac{\pi}{3} \\
0 & 0 & 0 & 0 & 0 \\
0 & 0 & -x_{q} & 0 & 0 \\
0 & 0 & 0 & 0 & 0
\end{array}\right]\left[\begin{array}{c}
\Delta I_{d}^{(m)} \\
\Delta I_{f}^{(m)} \\
\Delta I_{q}^{(m)} \\
I_{f l}^{(m)} \\
E_{f}
\end{array}\right],}
\end{aligned}
$$

where $E_{f}=\frac{3 \sqrt{3} E}{\pi} \cos (\alpha-\pi / 6)$.

We make the calculation of the system coefficients of differential equations in the following sequence. We add a matrix column $\left[\begin{array}{lllll}1 & 0 & 0 & 0 & 0\end{array}\right]$ to the right part of equations (13) instead of the existing matrix column with variables. We assume that $k=6 n$ concerning variables with upper index $c$ and we add to each of them the results of calculation according to formula (11). Thus, we obtain the column of system coefficients of differential equations at the final difference $\Delta I_{d}^{(m)}$. Then we substitute a matrix $\left[\begin{array}{lllll}0 & 1 & 0 & 0 & 0\end{array}\right]$ and so on. The following system of differential equations is obtained at the number of members of row $N=55$ and the control angle $\alpha=1$ radian for the accepted parameters:

$$
\begin{gathered}
{\left[\begin{array}{l}
I_{d l}^{(m)} \\
I_{f l}^{(m)} \\
I_{q l}^{(m)}
\end{array}\right]=\left[\begin{array}{ccccc}
180.36 & 431.69 & 0.58601 & 0.27693 & -315.69 \\
-301.56 & -720.22 & 0.034457 & -0.46168 & 526.32 \\
-4.9849 & -9.6852 & -0.51573 & -0.0057363 & 6.5394
\end{array}\right] \times} \\
\times\left[\begin{array}{lllll}
\Delta I_{d l}^{(m)} & \Delta I_{f l}^{(m)} & \Delta I_{q l}^{(m)} & I_{f l}^{(m)} & E_{f}
\end{array}\right]_{t}
\end{gathered}
$$

The lower index t means the transposed matrix.

This equation serves for the determination of the switching angle $\gamma$ :

$$
\cos (\alpha+\gamma-\pi / 6)=\left(1-\frac{6 x_{c}}{\pi\left(r_{f s}-3 \gamma r_{c} / 2 \pi+3 x_{c} / \pi\right)}\right) \cos (\alpha-\pi / 6) \text {. }
$$

Equations (14) now need to be written with respect to finite differences. Using the same algorithm (except for summation), we find that

$$
\left[\begin{array}{l}
\Delta I_{d}^{(m)} \\
\Delta I_{f}^{(m)} \\
\Delta I_{q}^{(m)}
\end{array}\right]=\left[\begin{array}{cccc}
-0.67421 & -0.39295 & -0.79238 & -0.58020 \\
0.28235 & 0.16254 & 0.33175 & 0.97371 \\
1.2143 & 0.73470 & -0.51012 & 0.0020833
\end{array}\right]\left[\begin{array}{c}
I_{d l}^{(m)} \\
I_{f l}^{(m)} \\
I_{q l}^{(m)} \\
E_{f}
\end{array}\right] .
$$


The calculation results of the transition process for the reference method and the equations (15) are given in Fig. 3 at $\alpha=1$ and $\alpha=2$.

\section{DISCUSSION}

The values of currents of the reference model are caused only in switching points and connected for the descriptive reasons by continuous bending. The values of currents of the discrete model are caused in the form of circles.

The step of discretization is set by the diagram of thyristor exciters of the synchronous machine. Six points for the period of industrial frequency are quite sufficient for adequate display of electromagnetic transition process. The local transient process can be restored in each interval of discretization, if necessary. In this case, the initial values of the variables are the values of discrete variables of the previous interval.

The comparison shows that the simplified accounting of the exciter is quite correct both at low and at high control angles.

a) $I$

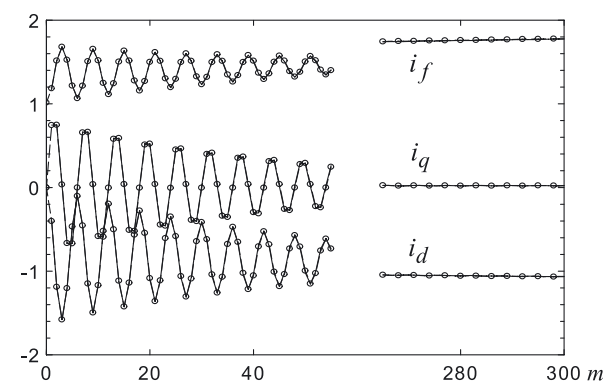

b) $I$

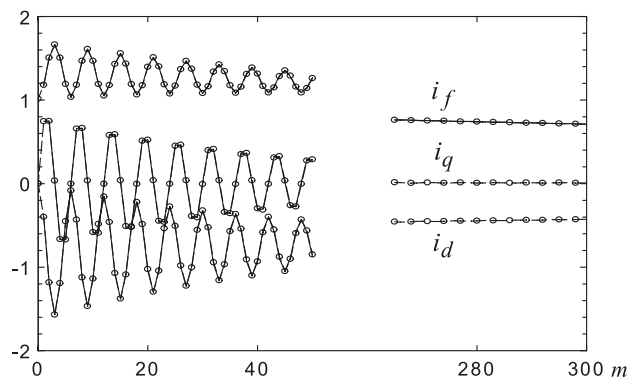

Fig. 3. Currents $i_{d}, i_{f}, i_{q}$ of the synchronous generator calculated in the reference and discrete mathematical models.

$\mathrm{a}$ - the angle of management, $\alpha=1 ; b-$ the angle of management, $\alpha=2$;

\section{CONCLUSION}

Thus, the local Fourier transform allows creating the mathematical model of the dynamoelectric and gate system, which initially represents the system of variable structure in a finite-difference type of constant structure. In this case, information on a transient phenomenon is provided in switching points at a frequency of 6 times during the industrial frequency (a bridge circuit of rectification). The present research has provided both numerical and analytical opportunities for further use of the obtained mathematical model for research of transient phenomena in electrical power systems without introduction of the simplifying assumptions in relation to gate drivers.

\section{ACKNOWLEDGEMENTS}

The presented results have been obtained in the scientific research "Methods of Increase of Reliability and Quality of Electric Power Supply in Distribution Net- 
works" (the task number 2014/448 on the implementation of government works in the field of scientific activities of the base portion of the state task of the Ministry of Education and Science of Russia).

The research has been supported by the autonomous non-profit organisation "Kazan Open University Talent 2.0”.

\title{
REFERENCES
}

1. Boldea, I., \& Tutelea, L.N. (2009). Electric Machines: Steady State, Transients, and Design with MATLAB. New York: CRC Press, Taylor \& Francis.

2. Kovacs, P.K. (1984). Transient Phenomena in Electrical Machines (1st ed.). Budapest: Akadémiai Kiadó.

3. Lipo, T.A. (2012). Analysis of Synchronous Machines (2nd ed.). Florida: CRC Press.

4. Simões, M.G., \& Farret, F.A. (2015). Modeling and Analysis with Induction Generators (3rd ed.). Florida: CRC Press, Taylor \& Francis Group.

5. Milano, F. (2010). Power System Modelling and Scripting. London: Springer-Verlag Limited.

6. Sood, V.K. (2004). HVDC and FACTS Controllers. Applications of Static Converters in Power Systems. Boston: Kluwer Academic Publishers.

7. Kolcun, M., Griger, V., \& Mühlbacher, J. (2003). Electric Power System Operation Control. Czech Republic: Pilsen.

8. Kolcun, M., Mühlbacher, J., \& Haller, R. (2004). Mathematical Analysis of Electrical Networks. Prague: BEN - technica literatura.

9. Takeuchi, T.J. (1968). Theory of SCR Circuit and Application to Motor Control. Tokyo: Electrical Engineering College Press.

\section{SINHRONO MAŠĨNU AR VĀRSTU IEROSMES SISTĒMĀM MATEMĀTISKĀ MODELĒŠANA, IZMANTOJOT VIETĒJO FURJĒ TRANSFORMĀCIJU}

\author{
A. Fedotovs, E. Fedotovs, K. Bahtejevs
}

Kopsavilkums

Raksta autori piedāvā elektrisko mašīnu ar tiristoru ierosinātāju matemātiskās modelēšanas metodi, izmantojot vietējo Furjē transformāciju. Pētījums parāda, ka šĩ metode ḷauj pārslēgties no mainīgās struktūras modeḷa uz pastāvīgās struktūras modeli. Pētījumā tiek izmantota pāreja no nepārtrauktiem mainīgajiem uz diskrētiem main̄̄gajiem lielumiem. Rakstā piedāvāts arī skaitlisks piemērs.

23.09.2016. 